\title{
Clinical expression of Holt-Oram syndrome on the basis of own clinical experience considering prenatal diagnosis
}

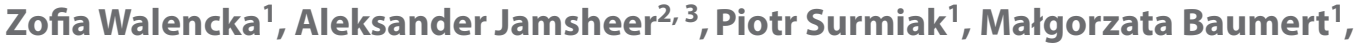 \\ Aleksandra Jezela-Stanek ${ }^{4}$, Andrzej Witek ${ }^{5}$, Anna Materna-Kiryluk2 , Anna Latos-Bieleńska², \\ Magdalena Socha², Anna Sowińska-Seidler² \\ ${ }^{1}$ Departament of Neonatology, School of Medicine in Katowice, Medical University of Silesia in Katowice, Poland \\ ${ }^{2}$ Department of Medical Genetics, Karol Marcinkowski University of Medical Sciences in Poznan, Poland \\ ${ }^{3}$ NZOZ Center for Medical Genetics GENESIS, Poznan, Poland \\ ${ }^{4}$ Department of Medical Genetics, Children's Memorial Health Institute, Warsaw, Poland \\ ${ }^{5}$ Departament of Gynecology and Obstetrics, School of Medicine in Katowice, Medical University of Silesia in Katowice, Poland
}

\begin{abstract}
Objectives: Holt-Oram syndrome manifests with defects of upper limbs, pectoral girdle and cardiovascular system. The aim of this paper was to present complex clinical picture of the syndrome and its variable expression on the example of the family diagnosed genetically on the neonatal ward, after proband's prenatal examination.

Maretial and methods: Nine family members were tested for TBX5 gene mutation.

Results: Four of family members were diagnosed with Holt-Oram syndrome and five had correct genetic test results. The diagnosis allowed to identify a genetic risk family and enabled to provide them with genetic counselling.

Conclusions: Diagnosis of Holt-Oram syndrome is possible as early as in prenatal period and it can be verified by genetic tests. Key words: Holt-Oram syndrome, congenital disorders, TBX5 gene
\end{abstract}

\section{INTRODUCTION}

Holt-Oram syndrome (HOS, OMIM 142900) is a genetic disease with autosomal dominant inheriting pattern. The estimated frequency of HOS is $1 / 100000$ births [1]. Syndrome is caused by loss-of-function mutations of TBX5 gene localized on the long arm of chromosome 12 (12q24.1) [2]. Clinical picture is very diversified. Dominant symptoms include defects of upper limbs and cardiovascular system. Diagnosis of Holt-Oram syndrome is possible through recognizing characteristic spectrum of defects prenatally, which has got a great meaning. It enables to plan appropriate time and place for labour to minimize the risk of complications [3, 4], especially in case of heart defects, which can be severe.
Verification of diagnosis by molecular tests can be followed by genetic counselling concerning evaluation of the risk of repeating the defect in the family, which is an important element of primary prevention [5]. Patients with the syndrome aren't always directed to genetic counselling.

\section{OBJECTIVES}

The aim of the study is to present a clinical picture of Holt-Oram syndrome and variability of its clinical expression, as well as possibility of diagnosing it prenatally and verifying by molecular tests.

The study describes family members with various clinical symptoms suggesting Holt-Oram syndrome. They weren't 


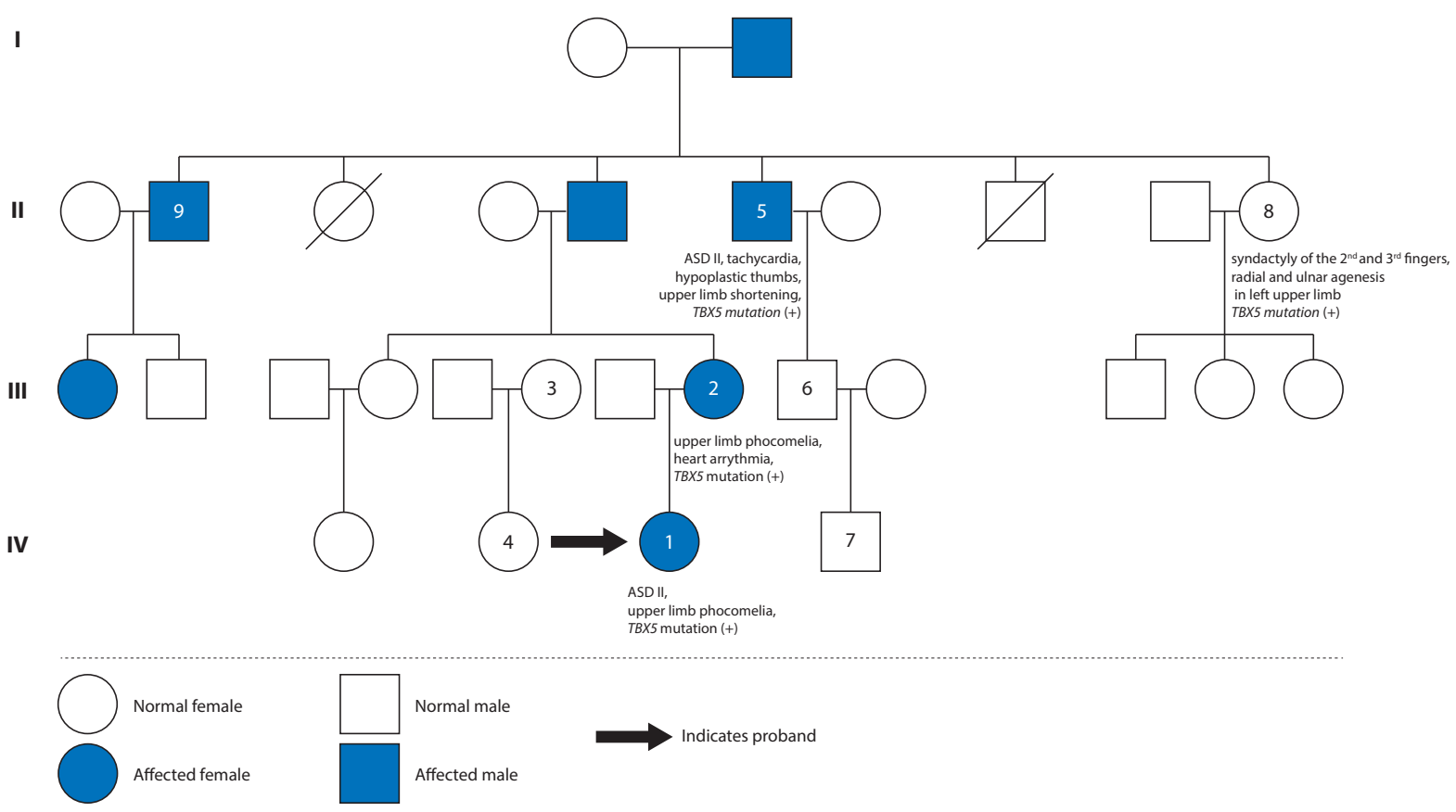

Figure 1. Pedigree structures of Holt-Oram Syndrome. Molecular tests were conducted in 9 numbered cases

diagnosed until prenatal genetic consultation, which took place after coexistence of limbs reduction defects and congenital heart disorders was observed. Analysis of family tree and conducted molecular tests allowed to diagnose syndrome among the family members (Fig. 1).

\section{MATERIAL AND METHODS}

Study included nine family members, who agreed to draw the blood sample. Four of them had Holt-Oram syndrome-suggesting clinical symptoms. Genetic material analysis and genetic counselling took place in Department of Medical Genetics of Poznan University of Medical Sciences. Tests were conducted as part of a science project financed by The National Science Centre'Accurate and exact CNV identification from targeted high-throughput sequence data in patients with congenital bilateral limb defects' (Nr: UMO-2011/03/D/NZ2/06136).

\section{Proband}

Female neonate born in 37th week of first pregnancy through caesarean section indicated by congenital fetus defect. Neonate's body mass was 2540 grams (> $10 \mathrm{c}$.), head circumference $32 \mathrm{~cm}$ (10 c.), body length $51 \mathrm{~cm}$ (90 c.). Apgar score was 7 points in first and 8 points in fifth minute of life. In physical examination and X-ray congenital upper limb defects with significant shortening were observed (Fig. 2). On the right three metacarpal bones, three phalanges and lack of forearm bones can be seen. Left limb consists of

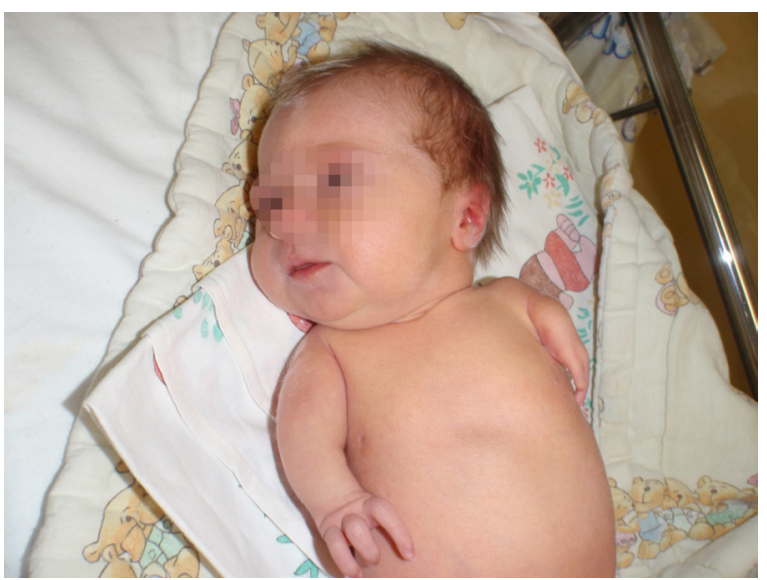

Figure 2. Upper limb defects with shortening. On the right upper limb three metacarpal bones, three phalanges and lack of forearm are observed. Left limb consists of metacarpal bones and shortened humerus, no forearm bones and phalanges

metacarpal bones and shortened humerus, but there are no forearm bones and phalanges. These defects were described in prenatal assessment. Considering syndrome associated cardiovascular disorders and the presence of heart murmur, case was consulted by cardiologist, who diagnosed atrial septal defect and patent ductus arteriosus, which is a regularity in this gestational age. In 6 weeks echocardiography was performed and the results were correct. During patient's stay in neonatal ward cranial and abdominal ultrasound was carried out with no deflections from physiology. Otoacoustic 
emissions test result was correct. Neonate was breastfed and appropriately gained weight.

\section{Proband's mother}

Mother at the age of 27 with upper limb phocomelia of significant degree: three fingers, lack of thumb, limb's lenght: $23 \mathrm{~cm}$. She also suffers from heart arrhythmia. Patient took vitamins through pregnancy which proceeded without severe problems. Proband's mother went through urinary tract infection treated by Duomox. She worked as a security guard during pregnancy. At the age of 18 she underwent a right hip joint replacement.

\section{Family members}

Other seven family members were examined and the symptoms were present in various intensities (Fig. 1). The study group along with proband and proband's mother consisted of five women and four men. Four of them had incorrect results of genetic test.

\section{Molecular tests}

After receiving consent on running tests, venous blood samples (with EDTA) were taken from all patients (neonate, mother and other seven family members). DNA isolation was conducted by salting out protein considering standard protocol. Proband had coding sequence of TBX5 gene (MIM ID*601620; GenBank NM_000192) analysis by Sanger's sequencing method, intragenic rearrangement examination of TBX5, SALL4 i SALL 1 by multiplex ligation-dependent probe amplification (MLPA) using P180-B1 kit (MRC-Holland). Array comparative genomic hybridization (array CGH), resolution of 1,4 billion per haploid genome (Roche-NimbleGen) was performed for precise detection of deletion range. To investigate if proband's deletion is segregated with phenotype, the rest of the family had MLPA examination.

\section{RESULTS}

Heterozygous deletion of whole coding sequence of TBX5 gene was detected in neonate's and mother's genomes by MLPA method, which confirmed diagnosis of Holt-Oram syndrome. Results of previously conducted sequencing of particular exons of TBX5 proband's gene excluded the presence of point mutation. Deletion of TBX5 included all exons of the gene, so additional array CGH was conducted to verify if no adjacent gene was deleted. Test confirmed that deletion of TBX5 gene was selective (deletion size 87,1 kb; genome coordinates by HG19 — chr12:114797295114884394). MLPA method detected identical deletion in genome of two other family members. No abnormalities were observed in five patients without clinical symptoms. All examined patients received genetic counselling, considering diagnosed disease and risk of passing it to their children. In general: nine patients were tested, four were diagnosed with Holt-Oram syndrome and five had correct test results (Fig. 3).

\section{DISCUSSION}

Holt-Oram Syndrom was described for the first time in 1960 by Mary Holt and Samuel Oram [6]. It manifests with wide spectrum of defects of upper limbs and cardiovascular system. It is inherited by autosomal dominant pattern, 74\% of patients who strictly fulfill the diagnostic criteria, have a mutation in TBX5 gene ascertained [7]. By other authors TBX5 mutations are identified only among around $30 \%$ of

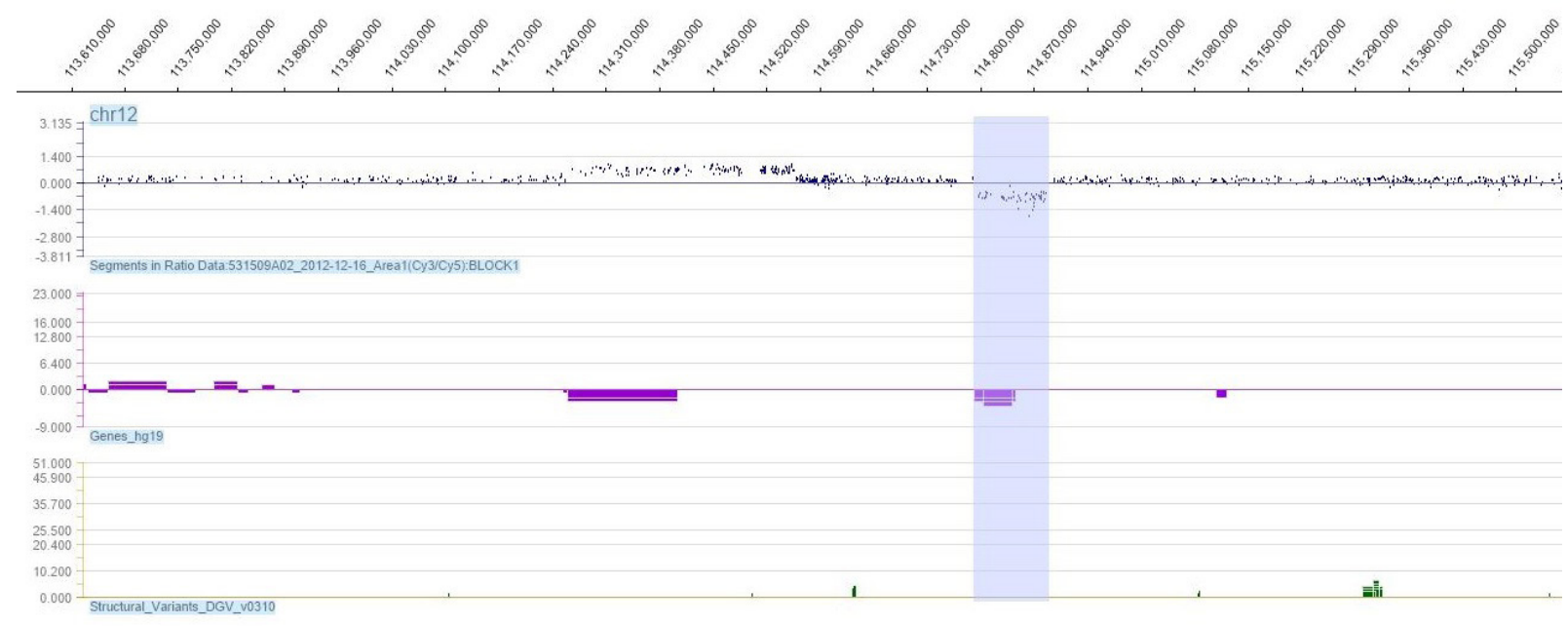

Figure 3. Proband had coding sequence of TBX5 gene (MIM ID*601620; GenBank NM_000192) analysis by Sanger's sequencing method, intragenic rearrangement examination of TBX5, SALL4 i SALL1 by multiplex ligation-dependent probe amplification (MLPA) using P180-B1 kit (MRC-Holland). Array comparative genomic hybridization (array CGH), resolution of 1,4 billion per haploid genome (Roche-NimbleGen) was performed. Test confirmed selective deletion of TBX5 gene (deletion size 87,1 kb; genome coordinates by HG19 — chr12:114797295- 114884394) 
patients [8]. Mentioned differences are a result of various HOS diagnostic criteria and patients' qualification to molecular tests. Most of cases occur among family members (around $60 \%$ ), whereas around $40 \%$ are results of de novo mutations [1].

Defects of upper limbs such as: thumb's, clavicle's and scapula's deformations, syndactyly and clinodactyly may not have influence on patient's functioning. Although, as it happened to our patients, major defects of upper limbs such as phocomelia (10\% of cases) are being observed [9]. The defects may be unilateral or bilateral, however radius is always affected. In majority of cases the disturbances are observed on the left side of the body [10]. Around $75 \%$ of patients with HOS are also affected with cardiovascular disorders [11, 12]. Most common are atrial septal defect, ventricular septal defect or stenosis of pulmonary vessels $[1,10$, 13]. Beside congenital heart diseases, various arrhythmias including conduction block, are observed [14]. Conduction defects are described independently of congenital heart diseases, as it happened in proband's mother case.

In so far as prognosis for patients with HOS is mainly connected with cardiovascular disturbances [15], the defects in skeletal system have got the major impact on patient's functioning. Although there is a possibility of substitution with a prosthesis, it's a very expensive treatment and does not always allow patients' independency. Genetic tests and counseling given to parents after taking their results, may ease making of conscious decision on reproduction. It's an essential part of primary prevention [15].

Prenatal diagnosis is possible even before $14^{\text {th }}$ week of pregnancy and should not cause difficulties, especially if major limb reductions occur [16]. Notice of abnormalities in cardiovascular system and in upper limbs needs to be differentiated with trisomy 13, 18 and others heart-hand syndromes, brachydactyly and long-thumb syndromes, disturbances connected with SALL4 gene mutations (Okihiro syndrome), Fanconi anemia, TAR (thrombocytopenia and absent radius) syndrome, some cases of VACTERL association or 22q11.2 deletion, 5q35.2-q35.3microduplications or embryopathies $[17,18]$.

Prenatal diagnostics play an important role in neonatology. Early prenatal identification of congenital defects allows to adequately plan date and place of labor, so the neonate can be given fast and specialist perinatal care. Coexisting of mother's and neonate's congenital defects obligate to diagnostic enhancement among family members, who had similar abnormalities. During taking family history it transpired that cardiovascular and limbs disorders, which suggested the diagnosis of Holt-Oram syndrom in both patients (proband and its mother), was noticed among other family members. They mainly affected various abnormalities in cardiovascular system and upper limbs morphology. Some family members had no HOS symptoms, but were afraid of carrying the defect and passing it to their children. Detailed medical history with few family members was taken and genetic tests were proposed to enable genetic consulting, which may help to make reproductive decisions. Patients with HOS have various clinical picture - may require permanent help or function well, depending on severity of defects. Some defects may be lethal [1].

As the case of the family shows, despite of symptoms of genetic disease among family members, genetic counselling nor genetic tests were offered. It's a proof of significance of prenatal diagnosis in identifying families with congenital diseases risk. It's also an example of a proper cooperation of neonatologists and dispensaries or genetic laboratories as neonatologists are the first doctors to diagnose neonates with congenital defect syndromes and families with genetic risk.

Considering variable clinical expression of Holt-Oram syndrome, even within one family, as seen in Table 1, phenotype prediction on the basis of genetic test result, TBX5 mutation, is not possible. This gene codes T-box 5 protein that is a transcription factor regulating expression of other genes responsible for development of heart and limbs. It is well known that missense mutations in T-Box $55^{\prime}$ end, which connects with major groove of targeted DNA sequence, are associated with more severe heart defects. Missense mutations in 3' end, that connects with minor groove, are linked to more serious limb defects $[11,19]$.

Family's genetic tests have showed deletion of whole TBX5 gene. It's an aberration present in about $2 \%$ of patients with existing HOS symptoms, which didn't have frequent point mutations detected (up to $70 \%$ of patients that fulfil strict HOS criteria) [7]. This kind of deletion currently isn't correlated with specific HOS phenotype.

Diagnosis of the syndrome permits to focus prophylactic care on the affected patients. Recommendations for people with Holt-Oram syndrome refer:

- ECG once a year (or more often in case of patients with conduction disorders or in a group of risk; alternately with Holter monitor);

- UCG once one to five years (depending on the morphological heart defect).

\section{CONCLUSIONS}

As presented in this study, Holt-Oram syndrome includes wide spectrum of upper limbs and pectoral girdle defects, as well as morphological and physiological disorders of cardiovascular system. Diagnosis of the syndrome is possible as early as in prenatal period and it can be verified by genetic tests. HOS should be considered in all cases of fetus' limb reduction defects, especially if coexisting with septal heart defects or cardiac conduction disorders. 


\section{REFERENCES}

1. Lichiardopol C, Militaru C, Popescu B, [et.al.]. Holt-Oram syndrome. Rom J Morphol Embryo. 2007, 48, 67-70.

2. Basson CT, Cowley GS, Solomon SD, [et al.]. The clinical and genetic spectrum of the Holt Orama syndrome (heart-hand syndrome). N Engl J Med. 1994, 330, 885-891.

3. Rekomendacje Sekcji Ultrasonografii Polskiego Towarzystwa Ginekologicznego w zakresie przesiewowej diagnostyki ultrasonograficznej w ciąży o przebiegu prawidłowym - 2015. Ginekol Pol. 2015, 86, 551-559.

4. Majewska E, Migielska-Wołyniec M, Franczak J, Styk M. Problem diagnostyki wad wrodzonych u noworodków i wcześniaków. Ginekol Pol. 1997, 68, 5b.

5. Latos-Bieleńska A, Materna-Kiryluk A, red. Wrodzone wady rozwojowe w Polsce w latach 2000-2002. Dane z Polskiego Rejestru Wrodzonych Wad Rozwojowych. OWN PAN, Poznań 2008.

6. Holt $\mathrm{M}$, Oram S. Familiar heart disease with skeletal malformations. $\mathrm{Br}$ Heart J. 1960, 22, 235-242.

7. Borozdin W, Bravo Ferrer Acosta AM, Bamshad MJ, [et.al.]. Expanding the spectrum of TBX5 mutations in Holt-Oram syndrome: detection of two intragenic deletions by quantitative real time PCR, and report of eight novel point mutations. Hum Mutat. 2006, 27, 975-976.

8. Cross SJ, Ching Y-H, Li QY, Armstrong-Buisseret L, [et al.]. The mutation spectrum in Holt-Oram syndrome. J Med Genet. 2000, 37, 785-787.

9. Tongsong T, Chanprapaph P. Prenatal sonographic diagnosis of Holt-Oram syndrome. J Clin Ultrasound. 2000, 28, 98-100.
10. Smith AT, Sack GH,Taylor GJ. Holt-Oram syndrome.J Pediatr. 1979, 95, 538-543.

11. Basson CT, Huang. T, Lin RC, [et al.]. Different TBX5 interactions in heart and limb defined by Holt-Oram syndrome mutations. Proc Natl Acad SciUSA. 1999, 96, 2919-2924.

12. Law KM, Tse KT. Prenatal sonographic diagnosis of familial Holt-Oram syndrome associated with type B interrupted aortic arch. Hongkong Med J. 2008, 14, 317-320.

13. Hurst JA, Hall CM, Baraitser M. The Holt-Oram syndrome. J Med Genet. 1991, 28, 406-410.

14. Sinha R, Nema D. Rare cardiac defect in Holt-Oram syndrome. CVJSA. 2012, 23, 2 .

15. Sunagawa S, Kikuchi A, Sano Y, [et al.]. Prenatal diagnosis of Holt-Oram syndrome: Role of 3-D ultrasonography. Congenital Anomalies 2009, 49, 38-41.

16. Muller LM, De Jong $G$, Van Heerden KM. The antenatal ultrasonographic detection of the Holt-Oram syndrome. S Afr Med J. 1985, 68, 313.

17. Gladstone I, Sybert VP. Holt-Oram syndrome. Penetrance of the gene and luck of maternal effect. Clin Genet. 1982, 21, 98-103.

18. Jamsheer A, Sowińska A, Simon D, [et. al.]. Bilateral radial agenesis with absent thumbs, complex heart defect, short stature, and facial dysmorphism in a patient with pure distal microduplication of 5q35.2-5q35.3. BMC Medical Genetics. 2013, 14, 13. doi: 10.1186/1471-2350-14-13.

19. Brassington AM, Sung SS, Toydemir RM, [et.al.]. Expressivity of Holt-Oram syndrome is not predicted by TBX5 genotype. Am J Hum Genet. $2003,73,74-85$. 